\title{
Simulation Modelling for Cold Storage Time-Space Optimization of Fresh Agricultural Products
}

\author{
${ }^{1}$ Dr.M.Vinoth, ${ }^{2}$ K.Mohamed Jasim and ${ }^{3}$ Dr.K.Abdus Samad \\ ${ }^{1}$ Assistant Professor, Faculty of Management, SRM Institute of Science and Technology, Kattankullathur, Tamil Nadu, India \\ ${ }^{2}$ Assistant Professor, Department of management studies, B S Abdur Rahman Crescent Institute of Science \& Technology, Vandalur,Chennai Tamil Nadu, India \\ 3 Principal \& Director, Agni College of Management and Design excellence, Dindigul, Tamil Nadu, India.
}

Correspondence Author: Dr.M.Vinoth Assistant Professor, Faculty of Management, SRM Institute of Science and Technology, Kattankullathur, Tamil Nadu, India

E-mail: vinosmit@gmail.com

Received date: April 2018, Accepted date: 28 July 2018, Online date: 5 August 2018

Copyright: (C) 2018 Dr.M.Vinothet al.,This is an open-access article distributed under the terms of the Creative Commons Attribution License, which permits unrestricted use, distribution, and reproduction in any medium, provided the original author and source are credited.

\begin{abstract}
The researchers examines and developed two different scenarios to identify and assess different cold storage time-space optimization of fresh agricultural products in Tamil Nadu, India. These overall time-space optimization method in logistics creates cost minimization, manpower planning, waste management, effective inventory techniques and quality maintenance. In scenario 1, the researchers consider how to maintain and measure time optimization in cold storage system of fresh agricultural products. In scenario 2, consider how to sustain and portion space optimization in cold storage system of fresh
\end{abstract}

Key words:Time-Space Optimization, Cost Minimization, Manpower Planning, Waste Management, Effective Inventory Techniques and Quality Maintenance.

\section{INTRODUCTION}

The worldwide worry over ecological dangers caused by different business tasks has driven analysts and experts to investigate assortment of ways to deal with diminish general carbon impression of a firm. Along these lines, the business associations have begun reframing their vital and operational arrangements to enhance the natural execution of the items and general assembling forms beginning from acquirement of items till the conveyance of completed products. Subsequently, an entire combination and effective coordination among every one of the individuals from store network including crude material providers, makers, wholesalers, and clients is required (Fahimnia and Jabbarzadeh 2006). To be a market pioneer, minimal effort and responsiveness are the key achievement factors Coordination exercises make high cost decreasing intensity of the organization, particularly for the remote creation base. Subsequently, coordinations exercises which are conveyance arranging, cargo forwarder and conveyance mode determination must be improved (Arayapan and Warunyuwong, 2010). A considerable lot of them don't comprehend the workmanship and study of coordinations. The science behind coordinations has constantly been there, anyway not generally known by anyone outside the business. Science is distinctively connected with every methodology inside a generation arrange since it anticipates that associations will design, realize, and execute strategies in light of free market action outlines, transportation costs, and stock levels to give a few cases. This suggests associations must grasp budgetary drivers, lean systems, deciding models, and resource use as a noteworthy part of their orchestrating shapes. Streamlining space inside a truck requires a significant measure of needing to lessen general costs. The craftsmanship behind progression starts truly and the inherent ability to get the most thing inside a limited measure of room. Space streamlining and convincing undertakings relies upon both experience and precise estimations.

\section{Literature Review:}

Simulation as a sociology inquire about device is characterized by Dawson (1962) as the development and control of a 'operating' model, that is, a physical or emblematic portrayal of all or a few parts of a social or mental process. For the social researcher, recreation prompts fabricating a model of an individual or gathering process and trying different things with the replication of this procedure by controlling the factors and their interrelationships inside the model. By building up a model, the parts and connections which are guessed as urgent are dreamy from the real world. Corridor (1976) takes note of: 'A model is a hypothesis. Acknowledgment of a PC program as "great" social hypothesis is reliant upon one's acknowledgment of the dependable scholar and his suspicions. It is imperative to know both (p. 186). To the degree that these suppositions are outlandish, the legitimacy of the model is diminished, and to the degree that a model contains formal hypothetical connections not exactly acquired, the pertinence of the model is diminished.' (p. 186). Displaying and Simulation are basic devices for the outline and examination of compartment terminals. A PC model can copy the exercises at different levels of subtle elements and catch the basic connections among the subsystems. Examination in light of the reproduction is especially helpful for planning new terminals, making changes to existing terminals, and assessing the advantages of new assets or effects of task approaches (Huang et al, 2008). Discrete Event Simulation (DES) models help to accomplish a few points: defeat scientific impediments of advancement approaches, bolster computergenerated systems/strategies and make them more justifiable, and bolster chiefs in day by day choice procedures through an "imagine a scenario where" approach (Carten and Luca, 2012. Legatet al, (2012) exhibit lining based portrayal of the housekeeping procedure in a genuine compartment terminal and comprehend it by discrete-occasion reproduction to I) survey the proficiency of the housekeeping activities under unanticipated occasions or process unsettling influences and ii) gauge the related profitability and holding up wonders which, thusly, influence the vessel turnaround time. Ports with multimodal transportation frameworks are specifically intricate as they regularly work with ships touching base to at least one terminals, numerous quay cranes, elastic tyred gantry cranes, and trucks conveying compartments of various kinds to terminals. With a few assets of various kinds operating and connecting, the framework can be complex to the point that it is difficult to anticipate the conduct of the framework and its execution measurements without the utilization of recreation. 


\section{Fresh Agricultural Products In India:}

The historical backdrop of Agriculture in India goes back to Indus Valley Civilization Era and even before that in a few sections of Southern India. Today, India positions second worldwide in cultivate yield. Horticulture and united divisions like ranger service and fisheries represented $13.7 \%$ of the GDP (total national output) in 2013, around half of the workforce. The financial commitment of horticulture to India's GDP is relentlessly declining with the nation's wide based monetary development. All things considered, horticulture is demographically the broadest financial division and assumes a critical part in the general financial texture of India. India traded \$38 billion worth of horticultural items in 2013, making it the seventh biggest rural exporter worldwide and the 6th biggest net exporter. A large portion of its agribusiness sends out serve creating and slightest created countries. Indian farming/agricultural and prepared sustenances are traded to in excess of 120 nations, basically in the Middle East, Southeast Asia, SAARC nations, the EU and the United States.

\section{Research Questions:}

1. How to maintain and measure time optimization in cold storage system of fresh agricultural products?

2. How to sustain and portion space optimization in cold storage system of fresh agricultural products?

Simulation:

Business simulations have had an imperative influence in administration improvement exercises for a long time, yet the universe of business is changing quickly and supervisors' duties are evolving as well. In the event that simulations are to stay important they should stay informed concerning these progressions, and ideally foresee them. Contends that while great "specialized" advancements have happened in the outline and utilization of business simulations in the course of the most recent couple of years, other, rather unique changes, need to occur or reproductions will chance ending up progressively immaterial (Fripp, 1997).Several research papers (Meketon 1987; Jacobson and Schruben 1989; Safizadeh 1990; Abramson2007; Alkhamis et al, 1999, Anderson and Ferris 2001; Andradóttir 2006; Ayvaz 2010; Balakrishna et al, 2007; Barton and Meckesheimer 2006; Bhatnagar 2005; Birge and Louveaux 2011; Carson and Maria 1997; Chen 1996; Chick 2006; Cohn et al, 1996) have identified the development of simulation model on time and space optimization.

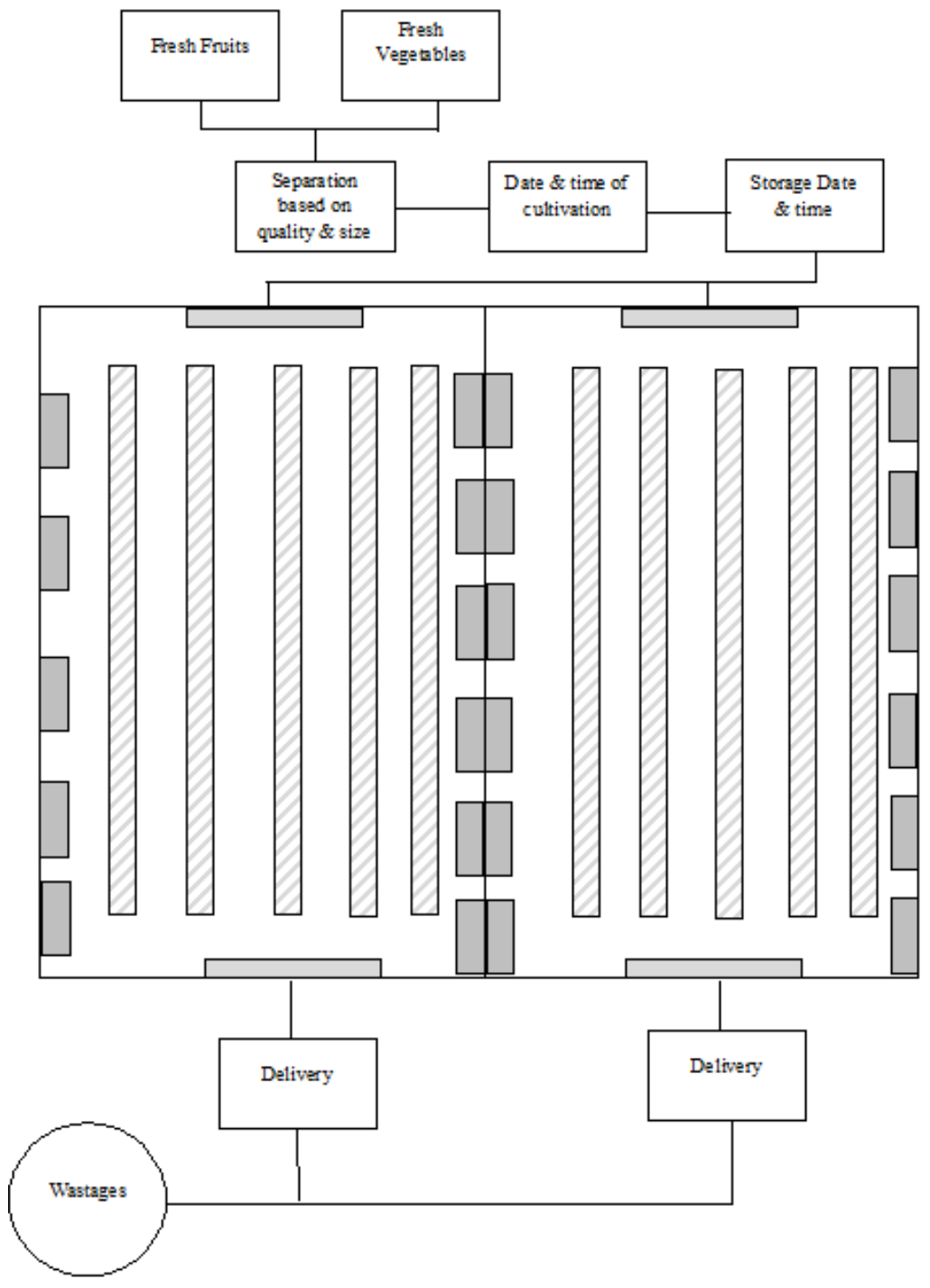

Fig. 1: Cold StorageSystem.

Model Establishment:

$\mathrm{j}$ : number of procurement centre for fresh agricultural products $[\mathrm{j}=(1,2,3,4 \ldots \ldots \ldots . \mathrm{n})]$

$\mathrm{k}$ : number of cold storage centre for fresh agricultural products $[\mathrm{k}=(1,2,3,4 \ldots \ldots \ldots \mathrm{n})]$

$\mathrm{Qd}=$ Customer Demand

Decision making variables

$Z j=\{1$, iftheprocurementcentrewasselected 
$X k=\left\{\begin{array}{c}1, \text { ifthecoldstoragewasselected } \\ 0, \text { otherwise }\end{array}\right.$

$X Z j k=\{1$, iftheprocurementcentredirectlysuppliestocoldstorage

$\mathrm{Fj}=$ Fixed time duration taken in the procurement centre

Fx $=$ Fixed space optimization taken in the cold centre

$\mathrm{Wj}=$ Variable cost

$\mathrm{Qjk}=$ Shipment quantity from procurement centre $\mathrm{j}$ to cold storage $\mathrm{k}$

$\mathrm{Qk}=$ Shipment quantity from cold storage $\mathrm{k}$ to customers

$\mathrm{Sj}=$ Distance between procurement centre $\mathrm{j}$ to cold storage $\mathrm{k}$

$\operatorname{Max} f=\sum_{j+1}^{j} F j Z k+\sum_{j+1}^{j} F j Z j+\sum_{z+1}^{Z} F x Z j+\sum_{z+1}^{Z} F x Z k+\sum_{j+1}^{j} F j X j+\sum_{j+1}^{j} F x X j----$

The objective function (1) maximize the time and space optimization, which is sum of the procurement centre, cold storage centre, Fixed time duration taken in the procurement centre and Fixed space optimization taken in the cold storage centre.

$\sum_{j+1}^{j} F j Z k * W j---$

$\sum_{j+1}^{j} F j Z j * W j---$

$\sum_{z+1}^{Z} F x Z j * W j---$

$\sum_{z+1}^{z} F x Z k * W j---$

$\sum_{j+1}^{j} F j X j * W j---$

$\sum_{j+1}^{j} F x X j * W j---$

Equations 2 to 7 denotes the variable cost involved to shipping fresh agricultural products from the procurement centre to cold storage centre.

$\sum_{j+1}^{j} F j X j \leq Q j k---$

$\sum_{j+1}^{j} F j X j \geq Q j k---$

Equations 8 and 9 examines the shipping quantity from procurement centre ' $\mathrm{j}$ ' to cold centre ' $\mathrm{k}$ '.

$\sum_{j+1}^{j} F j X k \leq Q k---$

$\sum_{j+1}^{j} F j X k \geq Q k----$

$\sum_{z+1}^{Z} F k Z k \leq Q k---$

$\sum_{j+1}^{j} F x Z k \geq Q k---$

Equations 10 to 13 explains the shipping quantity from cold storage ' $\mathrm{k}$ ' to customer destination.

$M a x f=\sum_{j+1}^{j} F j Z k * W j * \sum_{z+1}^{Z} F x Z k * W j * Q j k----$

$\operatorname{Maxf}=\sum_{j+1}^{j} F j Z k * W j * \sum_{z+1}^{Z} F x Z k * W j * Q k----$

Equations 14 and 15 are proposed simulations related to managerial considerations observed mostly in the time and space optimization for cold of fresh agricultural products in Tamil Nadu, India.

Conclusion:

In fresh vegetables and fruits storage system time-to-customer, space, inventory punctuality and throughput time, are important competition factors in maketo-order quality delivery. The fresh vegetables and fruits are usually complex systems consisting of storage because it is all perishable and highly consumable goods, which are cultivated in different farm lands, sometimes in different states. Naturally, the amount of time optimization and size of the space optimization is significant factor to reduce cost minimization, manpower planning, waste management, effective inventory techniques and quality maintenance. Here researcher, we have established simulation model for time and space optimization for cold of fresh agricultural products in Tamil Nadu, India. All this makes planning and management of time reduction and maximum space utilization in cold storage.

\section{REFERENCES}

Abramson, M.A., 2007. Nomadm version 4.5 user's guide. Air Force Institute of Technology, Wright-Patterson AFB, OH.

Alkhamis, T.M., M.A. Ahmed, V.K. Tuan, 1999. Simulated annealing for discrete optimization with estimation. European Journal of Operational Research, 116: $530-544$.

Anderson, E.J., M.C. Ferris, 2001. A direct search algorithm for optimization with noisy function evaluations. SIAM Journal on Optimization, $11: 837-857$.

Andradóttir, S., 2006. Simulation optimization. In J. Banks (Ed.), Handbook of simulation: Principles, methodology, advances, applications and practice, pp: 307-333.

Arayapan, K., P. Warunyuwong, 2010. Logistics optimization: Application of optimization modeling in inbound logistics. Retrieved from http://www.divaportal.org/smash/get/diva2:223629/FULLTEXT01 on Jan 21, 2014.

Armando Carten and Stefano de Luca, 2012. "Tactical and strategic planning for a container terminal: Modelling issues within a discrete event simulation approach", Simulation Modelling Practice and Theory, 21: 123-145. 
Ayvaz, M.T., 2010. A linked simulation-optimization model for solving the unknown groundwater pollution source identification problems. Journal of Contaminant Hydrology, 117(1-4): 46-59.

Balakrishna, R., C. Antoniou, M. Ben-Akiva, H.N. Koutsopoulos, Y. Wen, 2007. Calibration of microscopic traffic simulation models: Methods and application. Transportation Research Record: Journal of the Transportation Research Board, 1999(1): 198-207.

Barton, R.R., M. Meckesheimer, 2006. Metamodel-based simulation optimization. In S. Henderson \& B. Nelson (Eds.), Handbook in operations research and management science: Simulation, 13: 535-574.

Bhatnagar, S., 2005. Adaptive multivariate three-timescale stochastic approximation algorithms for simulation based optimization. ACM Transactions on Modeling and Computer Simulation, 15(1): 74-107.

Birge, J.R., F. Louveaux, 2011. Introduction to Stochastic Programming (2nd ed.). Berlin: Springer.

Carson, Y., A. Maria, 1997. Simulation optimization: Methods and applications. In S. Andradóttir, K.J. Healy, D.H. Winters, B.L. Nelson (Eds.), Proceedings of the 1997 winter simulation conference, pp: 118-126.

Chen, C.H., 1996. A lower bound for the correct subset selection probability and its application to discrete event system simulations. IEEE Transactions on Automatic Control, 41: 1227-1231.

Chick, S.E., 2006. Subjective probability and bayesian methodology. In S. G. Henderson \& B. L. Nelson (Eds.), Simulation, handbooks in operations research and management science, 13: 225-257.

Cohn, D.A., Z. Ghahramani, M.I. Jordan, 1996. Active learning with statistical models. Journal of Artificial Intelligence Research, 4: 129-145.

Dawson, R.E., 1962. Simulation in the social sciences. In Simulation in Social Science: Readings, ed. H. Guetzkow. Prentice Hall, Englewood Cliffs, NJ.

Fahimnia, B., A. Jabbarzadeh, 1976. Marrying supply chain sustainability and resilience: A matchHall, R.1. A system pathology of an organization: the rise and fall of the old Saturday Evening Post. Administrative Science Quarterly, 21: 185-211.

Jacobson, S.H., L.W. Schruben, 1989. Techniques for simulation response optimizationOperation Research Letters, 8: 1-9.

John Fripp, 1997. "A future for business simulations?", Journal of European Industrial Training, 21 (4): 138-142.

Meketon, M.S., 1987. Optimization in simulation: A survey of recent results. In: A. Thesen, H. Grant, \& W. D. Kelton (Eds.), Proceedings of the 1987 winter simulation conference, pp: 58-67.

Pasquale Legat, Rina Mary Mazza, Roberto Trunfio, 2012. "Simulation for performance evaluation of the housekeeping process". Proceedings of the Winter Simulation Conference, 2717-2725.

Huang, S.Y.,W.J. Hsu, C. Chen, R. Ye and S. Nautiyal, 2008. "Capacity Analysis of Container Terminals Using Simulation Techniques", International Journal of Computer Applications in Technology, 32(4): 246-253.

Safizadeh, M.H., 1990. Optimization in simulation: Current issues and the future outlook. Naval Research Logistics,37:807-825. 